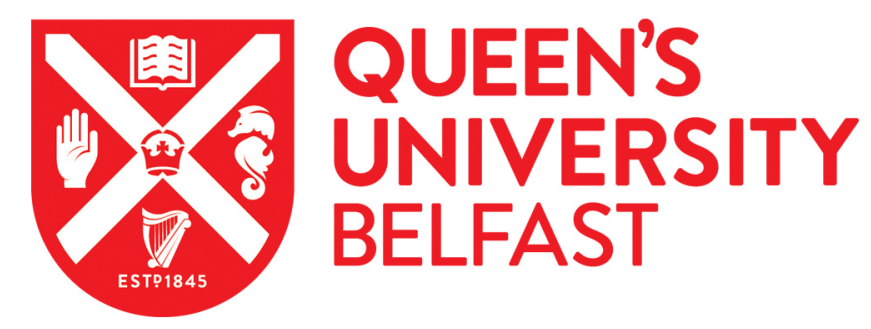

\title{
Imagined Contact and Mental Illness Stigma in an Asian Context: Bolstering the Effect and Examining the Impact of Factual Information
}

Lim, C., Au Kin Chung, A., \& Turner, R. (2019). Imagined Contact and Mental Illness Stigma in an Asian Context: Bolstering the Effect and Examining the Impact of Factual Information. Journal of Community and Applied Psychology. https://doi.org/10.1002/casp.2442

Published in:

Journal of Community and Applied Psychology

Document Version:

Peer reviewed version

Queen's University Belfast - Research Portal:

Link to publication record in Queen's University Belfast Research Portal

Publisher rights

Copyright 2019 Wiley. This work is made available online in accordance with the publisher's policies. Please refer to any applicable terms of use of the publisher.

\section{General rights}

Copyright for the publications made accessible via the Queen's University Belfast Research Portal is retained by the author(s) and / or other copyright owners and it is a condition of accessing these publications that users recognise and abide by the legal requirements associated with these rights.

Take down policy

The Research Portal is Queen's institutional repository that provides access to Queen's research output. Every effort has been made to ensure that content in the Research Portal does not infringe any person's rights, or applicable UK laws. If you discover content in the Research Portal that you believe breaches copyright or violates any law, please contact openaccess@qub.ac.uk. 
Running Head: IMAGINED CONTACT AND MENTAL ILLNESS STIGMA

Imagined Contact and Mental Illness Stigma in an East Asian Context: Bolstering the Effect and Examining the Impact of Negative Factual Information 


\begin{abstract}
Imagined contact can be effective at reducing social stigma. However, the effect may depend on the strength of the stigma held. We tested the robustness of imagined contact in an Asian setting where stigmatization of mental illness is stronger than in Western countries. In Experiment $1(n=167)$ with five conditions, only an enhanced version of positive imagined contact was able to decrease stigma towards people with schizophrenia. Given the potential discrepancy between imaginations and reality about experiences with stigmatised groups, in Experiment $2(n=121)$, we tested the hypothesis that after presenting participants with negative factual information about a mental illness group, imagined contact might backfire, resulting in more negative perceptions. However, enhanced imagined contact alongside factual message about schizophrenia did not increase stigma. The backfiring hypothesis was therefore not supported. Nevertheless, providing realistic information did negate the positive effects of enhanced imagined contact on stigma-reduction. In both experiments, we also showed that intergroup anxiety mediated the effect of enhanced imagined contact on various measures of stigma.
\end{abstract}

Keywords: imagined contact, stigma, mental illness, reducing prejudice 
Imagined Contact and Mental Illness Stigma in an East Asian Context: Bolstering the Effect and Examining the Impact of Negative Factual Information

People with mental illnesses are particularly stigmatised (Rüsch, Angermeyer, \& Corrigan, 2005), facing more discrimination than people with, for example, physical illnesses (Ormel et al., 2008; Socall \& Holtgraves, 1992). Given the significant implications of mental illness stigma, Corrigan and Penn (1999) emphasised the possibility of leveraging social psychological theories to promote social inclusion. In particular, intergroup contact is found to be highly effective in changing both attitudes and behaviour towards people with mental illnesses (Overton \& Medina, 2008). Recent evidence shows that an intergroup contact strategy based on simply mental imagery, imagined contact (Crisp \& Turner, 2009, 2012), is also an effective means of reducing mental illness stigma (e.g., West, Holmes, \& Hewstone, 2011).

Research on imagined contact generally demonstrates its benefits for improving intergroup relations (Miles \& Crisp, 2014,). However, its effect on reducing mental illness stigma warrants further investigation, especially in places where the stigma is strongly held. Another issue concerning imagined contact is that the likely discrepancy between imaginations and facts about people with mental illnesses may pose a question of the efficacy of the effect. The present research has two objectives. First, we examined the effect of imagined contact on perception of people having schizophrenia in an Asian context where mental illness stigma is stronger than in Western countries (Lauber \& Rössler, 2007). We tested whether a bolstered procedure of imagined contact is necessary in order to obtain an effect. Secondly, we examined whether providing factual information about schizophrenia will result in a backfiring of the imagined contact effect, whereby imagined contact results in more negative, rather than positive, outgroup perceptions. Below we outline the theoretical rationale for the research. 


\section{Intergroup Contact}

Allport's (1954) intergroup contact theory proposed that interactions between groups under optimal conditions of cooperation, common goals, equal status, and institutional support can effectively improve intergroup attitudes. Since its conception, intergroup contact has become one of psychology's best strategies for decreasing stigma (Dovidio, Gaertner, \& Kawakami, 2003) with strong support from meta-analytic findings (Pettigrew \& Tropp, 2006). Previous findings have shown that interpersonal contact with people with mental illnesses is effective in improving attitudes towards the group (Overton \& Medina, 2008; Penn, Kommana, Mansfield, \& Link, 1999).

\section{Imagined Intergroup Contact}

Recent studies have shown that just imagining contact can improve outgroup attitudes, and reduce intergroup anxiety and stereotyping (Crisp, Stathi, Turner, \& Husnu, 2009). Imagined intergroup contact is defined as "the mental simulation of a social interaction with a member or members of an outgroup category" (Crisp \& Turner, 2009, p.234). It involves simulating a positive social experience to activate concepts one normally associates with successful contact with outgroup members, such as feeling more at ease and less concerned about future intergroup contact. There are over 90 studies supporting the use of imagined contact in stigma-reduction (see Miles \& Crisp, 2013, for a meta-analysis). Imagined contact promotes intentions to engage in direct contact (Husnu \& Crisp, 2011), contact self-efficacy (Stathi, Crisp, \& Hogg, 2011), positive trait projection (Stathi \& Crisp, 2008), and the friendliness of behaviour during direct intergroup encounters (West, Turner, \& Levita, 2015). Imagined contact has also been shown to reduce stigmatising of people with schizophrenia (Stathi, Tsantila, \& Crisp, 2012; West et al., 2011), having a comparable effect to that of actual contact (Giacobbe, Stukas, \& Farhall, 2013). 
Imagined contact is beneficial in being a practical, inexpensive and easily implemented method for promoting social inclusion and combating stigma (Husnu \& Crisp, 2010). This makes it valuable when actual contact is not possible or unlikely, such as in highly segregated settings where there are limited opportunities to meet people from other groups (Miles \& Crisp, 2013). It may also have an added benefit of usefulness when there are opportunities for contact which are unrealised, helping to prepare individuals for real contact and encourage positive interactions with the outgroup (Crisp et al., 2009).

Although numerous researchers highlight caution when employing imagined contact (e.g., Crisp \& Turner, 2012; Stathi \& Crisp, 2008), there is scarce literature examining its limitations - existing research largely focuses on the positive effects of imagined contact (see West et al., 2011 for an exception). The present study explores ways in which the effectiveness of imagined intergroup contact can be constrained or undermined.

\section{Examining Limitations of Imagined Contact}

A limitation of imagined intergroup contact theory is that it requires specific positive circumstances to work and may become ineffective or counteractive otherwise (Crisp et al., 2009). West et al. (2011) found that when giving neutral instructions to participants, imagined contact actually increased intergroup anxiety. These findings are in line with studies which show that imagined contact works better when the imaginations are positive as compared to neutral (Stathi \& Crisp, 2008), as this guards against participants using their existing misconceptions to form a negative impression of the contact.

It appears that positivity is a necessary condition for imagined contact to be effective, at least for reducing strong stigmas such as those toward people with 
schizophrenia (West et al., 2011). Following this line of reasoning, in order to reduce prejudice toward a deeply stigmatized group, a stronger form of positive imagined contact may be required. This will be the case in places where stigma toward mental illness is held strongly. Research has shown that Asians tend to display greater stigmatisation of mental illnesses than Caucasians (Georg Hsu et al., 2008; Shamblaw, Botha, \& Dozois, 2015). Since most of the findings of imagined contact to date are based on Caucasian samples, it remains a question whether a stronger form of imagined contact is needed to reduce mental illness stigma in an Asian setting.

Another limitation of using imagined contact to combat stigma is that there is a likely discrepancy between imagination and reality. Research has shown that people's mental simulations tend to differ from real-life experiences as the former are often unrepresentative, abbreviated, decontextualized (Gilbert \& Wilson, 2007), and also subjective (Dror, 2005). Such characteristics means that the intended effect of a mental simulation may not translate into real-world behaviour. As such, the discrepancy between one's imagination and reality may impede the effectiveness of imagined contact.

Following the above, the divergence between imagined contact and realistic information may also result in attitudinal ambivalence, where an individual experiences both positive and negative attitudes towards the target group simultaneously (Jonas, Broemer, \& Diehl, 2000). Whilst the imagined contact task induces individuals to hold positive beliefs of the outgroup (Miles \& Crisp, 2013), the provision of realistic information about the outgroup may introduce a different perspective that creates a temporary dissonance. Thus, the presentation of realistic information following imagined contact can lead to quick alterations in outgroup attitudes. The new attitudes formed may be consistent with prevailing knowledge and beliefs. Subsequently, these 
new attitudes may deviate from the original positive beliefs brought about by imagined contact.

Another issue about imagined contact is that people are often unable to give an accurate forecast about how they would interact with another person. Research on affective and also behavioural forecasting has shown that people are poor predictors of their future emotions and reactions (Diekmann, 2008; Wilson \& Gilbert, 2005). During imagination, individuals cannot take into consideration or anticipate all the contextual details and situational forces that influence their response (Vallone, Griffin, Lin, \& Ross, 1990). When faced with information with different evaluative implications, people often experience a change in their attitudes and response (Glasman \& Albarracín, 2006). Such volatility of peoples' attitudes further impedes the ability of imagined contact to prevail when confronted with information not included in one's imagination.

Taken together, the discrepancy between imaginations and reality appears to limit imagined contact's ability to effect strong and lasting changes on people's attitudes (stereotypes) and behaviours (discrimination) towards stigmatised groups. Although imagined contact can influence people's present-moment thoughts and beliefs, there may be counter effects of attitudinal ambivalence and cognitive dissonance when factual information is provided. People may develop positive attitudes following imagined contact but realistic information relating to schizophrenia that are not necessarily negative may challenge these positive beliefs. To reconcile their conflicting emotions, people may alter the initial attitudes formed from imagined contact, and resulting attitudes following the presentation of factual information may be less favourable. This may result in a backfiring effect of the imagined contact task in which people develop higher levels of stigma towards the stigmatized group. 


\section{The Present Study}

Given the growing interest in using imagined contact as an intervention tool to combat stigma, there is a need for a more thorough evaluation of its effects on intergroup relations. First, with the evidence of imagined contact so far is based mostly on Western samples, we tested the effect in an Asian setting where mental illness stigma is presumably stronger. An enhanced version of imagine contact was added to see whether a bolstered procedure is necessary for reducing stigma that is deeply held. Secondly, we examined how imagined contact holds up when faced with realistic information about the target group. It was hypothesized that the effects of imagined contact on intergroup perception of a stigmatised group will backfire after processing realistic information about the group. Imagined contact followed by a factual message about the outgroup will lead to higher levels of stigma as compared to only going through the factual message without engaging in imagined contact. Experiment 1 examined the effects of imagined contact in decreasing schizophrenia-related stigma. Experiment 2 was conducted to replicate the findings with respected to the enhanced version of imagined contact, and to formally test the backfiring hypothesis.

\section{Experiment 1}

Following the standard positive imagined contact instructions as used in previous studies (e.g., Stathi et al., 2012), we first attempted to replicate the effect of imagined contact in decreasing stigma toward people having schizophrenia (West et al., 2011). We also added an enhanced condition of imagined contact to bolster the positivity of the imaginations formed. We expected that this condition would produce a stronger effect than the standard imagined contact condition. To test the backfiring hypothesis, we added a condition such that participants read a factual message about schizophrenia after engaging in imagined contact. We expected that stigma in this 
condition would not decrease and might even increase. There were two control conditions - one asking participants to engage in neutral imagination and one involved reading the factual message only. Finally, previous studies have shown that the effect of imagined contact on measures of stigma such as intergroup attitudes (West et al., 2011), outgroup evaluation (Turner, Crisp, \& Lambert, 2007), stereotyping and intentions to engage in future contact (Stathi et al., 2012) to be mediated by intergroup anxiety. This measure was therefore included to replicate previous results.

\section{Method}

Participants. The sample consisted of 167 participants, 46 males and 121 females, from a university in Singapore $\left(M_{\text {age }}=20.04, S D_{\text {age }}=1.55\right.$, Range $\left.=18-25\right)$. The participants either volunteered or received course credit for their participation.

Procedure. After providing informed consent, participants received different instructions depending on the experimental condition they were randomly assigned to. In the imagined contact condition $(n=32)$, participants were instructed: "Take a minute to imagine yourself meeting a person with schizophrenia for the first time. Imagine the interaction is relaxed, positive and comfortable. Imagine their appearance, the conversation that follows and, from what you learn, all the different ways you could classify them into different groups of people.” After one minute, participants were given 5 minutes to write down what they had just imagined with as much details as possible.

Participants assigned to the imagined contact with factual message condition ( $n$ $=32$ ) went through the same process, but were also immediately presented with a realistic and objective message about schizophrenia. The message was in the form of an infographic about schizophrenia compiled from factsheets published by sources including the National Institute of Mental Health from the US and Singapore's Institute of Mental Health. The information included (i) the definition of schizophrenia, (ii) 
factual information about its common symptoms, (iii) the causes and prevalence of schizophrenia, and (iv) the typical recovery process (Appendix A).

In the enhanced imagined contact condition $(n=35)$, positivity was integrated into the imagined scenario by explicitly instructing participants to imagine a pleasant interaction following West et al. (2011). Participants were also provided with more details of the imagined interaction with a person with schizophrenia. This ensured greater vividness and richer contextual cues of the imagined situation to enhance the effect of imagined contact (Husnu \& Crisp, 2010). The interaction partner was also chosen to allow for greater familiarity and connection. Specifically, participants were instructed: "Imagine yourself meeting a person with schizophrenia for the first time at a school event. You find out that this person is a final year Life Science student who stays in hall and got Dean's List last semester. He/she has a friendly and outgoing disposition and you end up having an engaging conversation with him/her. You learn more about the person and the interaction is relaxed, positive and comfortable." Participants were then given 5 minutes to write down the details of the interaction.

Previous studies on imagined contact have employed a wide range of control conditions such as neutral contact and non-relevant positive interaction (Stathi \& Crisp, 2008, Experiment 1 and 2), and no-contact control scenes (Turner et al., 2007, Experiment 1). As the significant benefits of imagined contact have been proven against all, the present study used the standard no-contact control scene. Specifically, participants in the control condition $(n=35)$ were told to imagine taking a walk in the outdoors and to note down the details of the scene.

Participants in the factual message only condition $(n=33)$ did not go through any imagination task and were directly presented with the infographic on schizophrenia identical to the one used in the imagined contact with factual message condition. This 
was done to serve as another control and to analyse the impact of realistic information in influencing the public's stigma towards people with mental illnesses. All participants subsequently completed a questionnaire. They were then debriefed about the true objectives of the study and thanked for their participation.

Dependent measures. Participants completed the following scales to measure their stigma towards people with mental illnesses.

Intergroup anxiety. Participants reported how “Awkward”, “Happy” (reversed), "Self-Conscious", "Competent" (reversed), and "Relaxed" (reversed) they would feel (1 $=$ not at all, $7=$ very $; \alpha=.54)$ if they were to meet a person with schizophrenia in the future (Stathi et al., 2012).

Attitudes. Participants were asked, "Describe how you feel about people with schizophrenia in general". They responded to six items on 7-point semantic differential scales $(\alpha=.82$; West, Hewstone, $\&$ Lolliot, 2014): cold-warm, positive-negative (reversed), friendly-hostile (reversed), suspicious-trusting, respectful-contempt (reversed), admiration-disgust (reversed). Higher scores indicated more positive attitudes.

Social closeness. Social closeness reflects people's willingness to interact with the outgroup. Adopting from the scale that oringally measured the reversed concept of social distance (Stuart \& Arboleda-Flórez, 2001), participants answered six items on a 4-point scale measuring their willingness to include people with schizophrenia in their social life $(1=$ definitely not, $4=$ definitely; $\alpha=.81)$. An example item was "I would be willing to be co-workers with someone with schizophrenia."

Intentions for future contact. Participants responded to five items on a 9-point scale $(1=$ not at all, $9=$ very; $\alpha=.87)$ examining their intentions for future interaction with people with schizophrenia (Stathi et al., 2012). An example item was "Thinking 
about the next time you find yourself in a situation where you could interact with a person with schizophrenia... how likely do you think it is that you would strike up a conversation?"

\section{Results and Discussion}

The descriptive statistics across the experimental conditions and the intercorrelations of the variables are listed in Table 1 and 2, respectively. First, one-way analysis of variance (ANOVA) was conducted on the four dependent measures. The results were nonsignifcant for the three stigma measures - attitudes: $F(4,162)=0.31, p$ $=.871$; social closeness: $F(4,162)=1.43, p=.225$; and intentions for future contact: $F(4,162)=1.48, p=.209$. However, for intergroup anxiety, there was a significant difference in the means across the conditions, $F(4,162)=3.52, p=.009$.

Further $t$-test results revealed that there was no significant difference on the three measures of stigma between the imagined contact condtion and the control condition $(p s>.12)$. There was also no significant difference between the imagined contact with factual message condition and the control condition $(p s>.13)$. As a result, our hypotheses regarding the effect of imagined contact and the backfiring of imagined effect followed by a factual message were not supported.

To probe the significant result for intergroup anxiety and to manage Type 1 error inflation, Tukey HSD tests were conducted for pairwise comparisons. Intergroup anxiety in the enhanced imagined contact condition $(M=3.99, S D=0.53)$ was significantly lower than both the imagined contact condition $(M=4.57, S D=0.73), p=$ .020 , and the control condition $(M=4.60, S D=0.79), p=.009$. However, levels of anxiety in the enhanced imagined contact condition did not significantly differ from in the imagined contact with factual message condition or in the factual message only condition $(p s>.12)$. 
Mediation analyses. The SPSS macro Process (Hayes, 2013) was used to test the meditating role of intergroup anxiety in the effect on imagined contact on the stigma measures. The significance of the indirect effect of imagined contact on the measures of stigma through intergroup anxiety was estimated with the bootstrap resamples set as 5000. For attitudes, the indirect effect of enhance imagined contact (vs. the control condition) through intergroup anxiety was .10, 95\% CI $[-.12, .36]$. For intentions for future contact, the indirect effect of enhanced imagined contact (vs. the control condition) through intergroup anxiety was $.40,95 \%$ CI $[.05, .90]$. For social closeness, the indirect effect of enhanced imagined through intergroup anxiety was .14, 95\% CI $[.04, .29]$. For intention for future contact and social closeness, as the confidence intervals did not include zero, the mediation effects were deemed significant (MacKinnon, Lockwood, \& Williams, 2004). Figure 1 shows the full results of testing the mediation.

Summing up, Experiment 1 shows that the standard imagined contact used in past studies was unable to reduce stigma towards a highly stigmatised group (people with schizophrenia). Imagined contact needed to be enhanced with the use of richer details, elaboration and integration of positivity to decrease stigma. In addition, instead of having a direct effect on reducing stigma, intergroup anxiety was found to mediate enhanced imagined contact's ability to improve intergroup relations. Through reduced intergroup anxiety, enhanced imagined contact had an indirect effect on improving intentions for future contact and social closeness. That said, Experiment 1 was unable to test the hypothesis on the backfiring effect given that standard imagined contact did not reduce stigma. Experiment 2 was conducted to see if current findings on enhanced imagined contact could be replicated. If enhanced imagined contact could effectively 
reduce stigma towards people with schizophrenia, then pairing it with realistic information would allow for the proper testing of the backfiring hypothesis.

\section{Experiment 2}

Experiment 2 comprised of three conditions - i) enhanced imagined contact, ii) enhanced imagined contact with factual message, and iii) control. Following from Experiment 1, enhanced imagined contact will show reduced mental illness stigma compared to the control condition. Additionally, we hypothesized that the enhanced imagined contact with factual message condition will backfire. It will be less able to decrease stigma as compared to both enhanced imagined contact and the control.

\section{Method}

Participants. The sample consisted of 121 participants, 42 males and 79 females, from a university in Singapore $\left(M_{\text {age }}=21.26, S D_{\text {age }}=1.69\right.$, Range $\left.=18-25\right)$. The participants received course credit for their participation.

Procedure. Participants were randomly assigned to one of three experimental conditions. The experimental materials of enhanced imagined contact, factual message, and control were identical to those employed in Experiment 1. To make the enhanced imagined contact and the control conditions comparable to the enhanced imagined contact with factual message condition, a filler passage on healthy eating (Appendix B) was used for the two conditions to parallel the factual message. Following the imagination task, participants were presented with an infographic on either schizophrenia for the factual message condition, or on healthy eating for the other two conditions. This ensured that everyone went through the same time interval following imagination before responding to measures of stigma. 
Dependent measures. The stigma measures were identical to those used in Experiment 1 . They included intergroup anxiety $(\alpha=.57)$, attitudes $(\alpha=.83)$, social closeness $(\alpha=.85)$, and intentions for future contact $(\alpha=.84)$.

\section{Results and Discussion}

A one-way ANOVA comparing the three conditions found no significant differences between the conditions on any of the dependent measures — intergroup anxiety: $F(2,118)=\mathrm{x} . \mathrm{xx}, p=.117$; attitudes: $F(2,118)=\mathrm{x} . \mathrm{xx}, p=.482$; social closeness: $F(2,118)=\mathrm{x} . \mathrm{xx}, p=.972$; and intentions for future contact: $F(2,118)=\mathrm{x} . \mathrm{xx}$, $p=.375$. However, a priori comparisons based on the hypotheses were conducted. Results from independent samples $t$-tests showed that following enhanced imagined contact, participants reported marginally lower intergroup anxiety $(M=4.26, S D=$ $0.85)$ as compared to those in the control condition $(M=4.63, S D=0.83), t(80)=-1.98$, $p=.051$. The results replicated those of Experiment 1 in demonstrating that enhanced imagined contact can reduce intergroup anxiety.

Comparatively, there were no significant differences between enhanced imagined contact with factual message and the control condition on any of the dependent measures $(p s>.10)$. Further comparisons showed that there were no significant differences between enhanced imagined contact with factual message and enhanced imagined contact on any of the dependent measures $(p s>.15)$. The results therefore did not support the backfiring hypothesis that enhance imagined contact with factual message would result in higher stigmatization of mental illness as compared to either the control or the enhanced imagined contact without factual message condition.

Mediation analyses. Similar to Experiment 1, mediation analysis was conducted to determine whether intergroup anxiety mediated the effects of enhanced imagined contact (see Table 4 for correlations between the measures). In order to 
compare the three experimental conditions in the analysis, the use of dummy coding following Hayes and Preacher (2014) was adopted. Two dummy-coded variables were formed with the control condition as the reference group (i.e., D1: enhanced imagined contact $=1$, otherwise $=0 ;$ D2: enhanced imagined contact with factual message $=1$, otherwise $=0$ ). As shown in Figure 2, intergroup anxiety was found to mediate the relationship between enhanced imagined contact on all the three measures of stigma. For attitudes, the indirect effect was .13, 95\% CI [.02, .34]. For social closeness, the indirect effect was $.11,95 \%$ CI $[.01, .25]$. For intentions for future contact, the indirect effect was $.17,95 \%$ CI $[.02, .42]$. Comparatively, intergroup anxiety did not mediate the relationship between enhanced imagined contact with factual message on all the three measures of stigma. As all the 95\% CIs included zero, the indirect effects were not significant. Figure 2 shows the complete results of the mediation analysis.

Experiment 2 was able to replicate findings of Experiment 1 in showing that enhanced imagined contact could effectively decrease participants' anxieties towards people with schizophrenia. In Experiment 1, reducing intergroup anxiety was found to mediate the effects of enhanced imagined contact on two of the three measures of stigma - intentions for future contact and social closeness. Experiment 2 not only replicated this finding but also extended it in demonstrating that intergroup anxiety also mediated the effects of enhanced imagined contact on attitudes. Meanwhile, the enhanced imagined contact with factual message condition did not significantly differ from the control condition. This indicates that there was no backfiring effect - being presented with a factual message following enhanced imagined contact did not result in more negative beliefs about the target group. Nonetheless, the factual message was found to negate the positive effect that enhanced imagined contact had in decreasing intergroup anxiety. 


\section{General Discussion}

Previous studies have suggested that imagined contact is an effective means of reducing intergroup bias (Stathi et al., 2012). The first objective of the present research was to examine whether the same is true in an Asian setting where mental illness stigma is high in comparison to in Western countries. Experiment 1 found that the imagined contact task did not replicate past findings in decreasing stigmatising of people with schizophrenia using the standard imagined contact task. The research findings that were derived from European or American participants may therefore not generalize to societies where there are higher levels of mental illness stigma such as Asia (Rao, Feinglass, \& Corrigan, 2007). Given that the present study sampled an Asian population from Singapore, participants possibly held higher levels of stigma towards people with schizophrenia. This might have then contributed to the failure of the standard imagined contact task in combating stigma.

An advantage of using the imagined contact task is its malleability and controllability (West et al., 2011). This allowed for adjustment to the original task in the enhanced imagined contact condition. Following from previous papers that strengthened the effects of imagined contact by getting participants to close their eyes (Husnu \& Crisp, 2011) or via enhancing the vividness of the imagined scenario (Husnu \& Crisp, 2010), providing clearer instructions on desired positive imaginations was able to create more robust effects on stigma-reduction. The two reported studies found support for the hypothesis that enhanced imagined contact could reduce stigma towards people with schizophrenia. Nevertheless, it should be noted that across the two studies, imagined contact did not exert an effect on the stigma measures directly. The effect was indirect through lowering intergroup anxiety as revealed in the mediation analysis. 
The second objective of the present research was to examine how imagined contact would hold up when confronting with factual information about the stigmatized group. While the backfiring hypothesis was not supported, Experiment 2 demonstrated that the effects of imagined contact might be weaker than previously suggested. The effects of enhanced imagined contact on stigma-reduction could be easily negated by the presentation of factual information of schizophrenia. There are some possible explanations for this. First, imagined contact could have only instilled only weak positive attitudes and feelings towards people with schizophrenia. Thus, presenting the factual message about schizophrenia may outweigh the effect of imagined contact. Second, since individuals tend to hold negative stereotypes towards people with mental health conditions, these beliefs may align with factual information more easily, thus negating the positive effect of imagined contact. In addition, in line with the concept of confirmation bias (Nickerson, 1998), where people tend to focus on facts that support their existing stereotypes, any factual information might intensify negative views towards people with schizophrenia. Therefore, imagined contact loses any positivity it might have accorded. Despite this, the mechanisms outlined above may not be strong enough to trigger a backfiring effect, rendering the hypothesis unsupported.

\section{Limitations and Future Directions}

One possible limitation of the present research is the one-off usage of a short imagined contact task as a means of combating long-held knowledge and attitudes towards people with schizophrenia. Cameron, Rutland, Turner, Homan-Nicolas, and Powell (2011) have highlighted the importance of developing imagined contact interventions to be long-lasting. Repeated and long-term exposure to imagined contact is a key to enhancing its effects. Vezzali, Capozza, Stathi, and Giovannini (2012) found that the use of multiple imagined contact sessions across three weeks with children led 
to lasting attitude change towards the outgroup. Future research might therefore include longer intervention and continual simulation of positive interactions for a more significant reduction in mental illness stigma.

The factual message about schizophrenia may be viewed by some as conveying very negative information about the people suffering from it (e.g., disorganized speech, withdrawing from social interactions). We have been careful in extracting information of the disorder in order to formulate a neutral description. It seems that symptoms of any disorder are more naturally associated with a negative rather than a positive valence. If it was the case, the factual message should go in favour to the backfiring hypothesis when it was paired with imagined contact. However, the results did not show any effect of the factual message increasing stigma as compared to the control condition. We therefore believe that the factual message used in the studies did not portray a negative image of people with schizophrenia.

Additionally, the present study used a purely factual message that details what the condition of schizophrenia is but not what an interaction with an individual with schizophrenia might entail to carry out reality-testing. This could have contributed to the absence of a backfiring effect as there might have been no direct conflict between the attitudes induced by imagined contact and those from the factual message. A related point is that our studies did not control for participants' previous experience of interacting people with schizophrenia. It could be that the backfiring effect would emerge for people with low actual contact with schizophrenia patients or having very limited knowledge about the disorder. Future research can better test the hypothesis on the backfiring effect by following the imagined contact task with actual contact with an individual with schizophrenia. This can involve having participants interact with a confederate that is identified as being diagnosed with schizophrenia. Also, previous 
contact with people suffering from schizophrenia can be measured and examined as a moderator. These improvements help examine the backfiring hypothesis more precisely.

\section{Conclusions}

Social stigma towards people with schizophrenia continues to negatively and unfairly affect the quality of life for these individuals. Past research recommend that policymakers and educators make use of the imagined contact strategy to promote tolerance and acceptance among people and communities (Vezzali et al., 2012). In the current study, conducted among an East Asian sample where levels of mental illness stigma are high, imagined contact needed to be enhanced for an effective reduction in intergroup anxiety, and even so, its effects were negated by realistic information. Therefore, using imagined contact as an intervention tool requires careful handling and manipulation, particularly where stigma levels are high. An important direction for future research includes efforts to structure imagined contact to ensure that positive realistic information is harnessed and negative realistic information countered. This will help to ensure that imagined contact is maximally effective in achieving valuable effects of stigma-reduction. 


\section{References}

Allport, G. W. (1954). The nature of prejudice. Cambridge, MA: Addison-Wesley.

Cameron, L., Rutland, A., Turner, R., Homan-Nicolas, R., \& Powell, C. (2011).

'Changing attitudes with a little imagination': Imagined contact effects on young children "s intergroup bias. Anales de Psicologia, 27, 708-717

Corrigan, P. W., \& Penn, D. L. (1999). Lessons from social psychology on discrediting psychiatric stigma. American Psychologist, 54, 765-776.

https://doi.org/10.1037//0003-066X.54.9.765

Crisp, R. J., Stathi, S., Turner, R. N., \& Husnu, S. (2009). Imagined intergroup contact: Theory, paradigm and practice. Social and Personality Psychology Compass, 3, 1-18. https://doi.org/10.1111/j.1751-9004.2008.00155.x

Crisp, R. J., \& Turner, R. N. (2009). Can imagined interactions produce positive perceptions? Reducing prejudice through simulated social contact. American Psychologist, 64, 231-240. https://doi.org/10.1037/a0014718

Crisp, R. J., \& Turner, R. N. (2012). Imagined intergroup contact. In G. Hodson \& M. Hewstone (Eds.), Advances in intergroup contact (pp. 135-151). Hove, UK: Psychology Press.

Diekmann, K. A. (2008). "She did what? There is no way I would do that!" The potential interpersonal harm caused by mispredicting one's behavior. Journal of Business Ethics, 80, 5-11. https://doi.org/10.1007/s10551-007-9437-x

Dovidio, J. F., Gaertner, S. L., \& Kawakami, K. (2003). Intergroup contact: The past, present, and the future. Group Processes \& Intergroup Relations, 6, 5-21. https://doi.org/10.1177/1368430203006001009 
Dror, I. E. (2005). Perception is far from perfection: The role of the brain and mind in constructing realities. Behavioral and Brain Sciences, 28, 763-763. https://doi.org/10.1017/S0140525X05270139

Georg Hsu, L., Wan, Y. M., Chang, H., Summergrad, P., Tsang, B. Y., \& Chen, H. (2008). Stigma of depression is more severe in Chinese Americans than Caucasian Americans. Psychiatry: Interpersonal and Biological Processes, 71, 210-218. https://doi.org/10.1521/psyc.2008.71.3.210

Giacobbe, M. R., Stukas, A. A., \& Farhall, J. (2013). The effects of imagined versus actual contact with a person with a diagnosis of schizophrenia. Basic and Applied Social Psychology, 35, 265-271.

https://doi.org/10.1080/01973533.2013.785403

Gilbert, D. T., \& Wilson, T. D. (2007). Prospection: Experiencing the future. Science, 317, 1351-1354. https://doi.org/10.1126/science.1144161

Glasman, L. R., \& Albarracín, D. (2006). Forming attitudes that predict future behavior: A meta-analysis of the attitude-behavior relation. Psychological Bulletin, 132, 778-822. https://doi.org/10.1037/0033-2909.132.5.778

Hayes, A. F. (2013). Introduction to mediation, moderation, and conditional process analysis : A regression-based approach. New York: Guilford.

Hayes, A. F., \& Preacher, K. J. (2014). Statistical mediation analysis with a multicategorical independent variable. British Journal of Mathematical and Statistical Psychology, 67, 451-470. https://doi.org/10.1111/bmsp.12028

Husnu, S., \& Crisp, R. J. (2010). Elaboration enhances the imagined contact effect. Journal of Experimental Social Psychology, 46, 943-950. https://doi.org/10.1016/j.jesp.2010.05.014 
Husnu, S., \& Crisp, R. J. (2011). Enhancing the imagined contact effect. Journal of Social Psychology, 151, 113-116. https://doi.org/10.1080/00224541003599043

Jonas, K., Broemer, P., \& Diehl, M. (2000). Attitudinal ambivalence. European Review of Social Psychology, 11, 35-74. https://doi.org/10.1080/14792779943000125

Lauber, C., \& Rössler, W. (2007). Stigma towards people with mental illness in developing countries in Asia. International Review of Psychiatry, 19, 157-178. https://doi.org/10.1080/09540260701278903

MacKinnon, D. P., Lockwood, C. M., \& Williams, J. (2004). Confidence limits for the indirect effect: Distribution of the product and resampling methods. Multivariate Behavioral Research, 39, 99-128. https://doi.org/10.1207/s15327906mbr3901_4

Miles, E., \& Crisp, R. J. (2013). A meta-analytic test of the imagined contact hypothesis. Group Processes \& Intergroup Relations, 17, 3-26. https://doi.org/10.1177/1368430213510573

Nickerson, R. S. (1998). Confirmation bias: A ubiquitous phenomenon in many guises. Review of General Psychology, 2, 175-220. https://doi.org/10.1037/10892680.2.2.175

Ormel, J., Petukhova, M., Chatterji, S., Aguilar-Gaxiola, S., Alonso, J., Angermeyer, M. C., ... Kessler, R. C. (2008). Disability and treatment of specific mental and physical disorders across the world. The British Journal of Psychiatry, 192, 368375. https://doi.org/10.1192/bjp.bp.107.039107

Overton, S. L., \& Medina, S. L. (2008). The stigma of mental illness. Journal of Counseling \& Development, 86, 143-151. https://doi.org/10.1002/j.15566678.2008.tb00491.x

Penn, D. L., Kommana, S., Mansfield, M., \& Link, B. G. (1999). Dispelling the stigma of schizophrenia: II. The impact of information on dangerousness. 
Schizophrenia Bulletin, 25, 437-446.

https://doi.org/10.1093/oxfordjournals.schbul.a033391

Pettigrew, T. F., \& Tropp, L. R. (2006). A meta-analytic test of intergroup contact theory. Journal of Personality and Social Psychology, 90, 751-783. https://doi.org/10.1037/0022-3514.90.5.751

Rao, D., Feinglass, J., \& Corrigan, P. (2007). Racial and ethnic disparities in mental illness stigma. The Journal of Nervous and Mental Disease, 195, 1020-1023. https://doi.org/10.1097/NMD.0b013e31815c046e

Rüsch, N., Angermeyer, M. C., \& Corrigan, P. W. (2005). Mental illness stigma: Concepts, consequences, and initiatives to reduce stigma. European Psychiatry, 20, 529-539. https://doi.org/10.1016/j.eurpsy.2005.04.004

Shamblaw, A. L., Botha, F. B., \& Dozois, D. J. A. (2015). Accounting for differences in depression stigma between Canadian Asians and Europeans. Journal of CrossCultural Psychology, 46, 597-611. https://doi.org/10.1177/0022022115575076

Socall, D. W., \& Holtgraves, T. (1992). Attitudes toward the mentally ill: The effects of label and beliefs. The Sociological Quarterly, 33, 435-445. https://doi.org/10.1111/j.1533-8525.1992.tb00383.x

Stathi, S., \& Crisp, R. J. (2008). Imagining intergroup contact promotes projection to outgroups. Journal of Experimental Social Psychology, 44, 943-957. https://doi.org/10.1016/j.jesp.2008.02.003

Stathi, S., Crisp, R. J., \& Hogg, M. A. (2011). Imagining intergroup contact enables member-to-group generalization. Group Dynamics: Theory, Research, and Practice, 15, 275-284. https://doi.org/10.1037/a0023752

Stathi, S., Tsantila, K., \& Crisp, R. J. (2012). Imagining intergroup contact can combat mental health stigma by reducing anxiety, avoidance and negative stereotyping. 
Journal of Social Psychology, 152, 746-757.

https://doi.org/10.1080/00224545.2012.697080

Stuart, H., \& Arboleda-Flórez, J. (2001). Community attitudes toward people with schizophrenia. Canadian Journal of Psychiatry, 46, 245-252. https://doi.org/10.1177/070674370104600304

Turner, R. N., Crisp, R. J., \& Lambert, E. (2007). Imagining Intergroup Contact Can Improve Intergroup Attitudes. Group Processes \& Intergroup Relations, 10, 427-441. https://doi.org/10.1177/1368430207081533

Vallone, R. P., Griffin, D. W., Lin, S., \& Ross, L. (1990). Overconfident prediction of future actions and outcomes by self and others. Journal of Personality and Social Psychology, 58, 582-592. https://doi.org/10.1037/0022-3514.58.4.582

Vezzali, L., Capozza, D., Stathi, S., \& Giovannini, D. (2012). Increasing outgroup trust, reducing infrahumanization, and enhancing future contact intentions via imagined intergroup contact. Journal of Experimental Social Psychology, 48, 437-440. https://doi.org/10.1016/j.jesp.2011.09.008

West, K., Hewstone, M., \& Lolliot, S. (2014). Intergroup contact and prejudice against people with schizophrenia. Journal of Social Psychology, 154, 217-232. https://doi.org/10.1080/00224545.2014.888327

West, K., Holmes, E., \& Hewstone, M. (2011). Enhancing imagined contact to reduce prejudice against people with schizophrenia. Group Process \& Intergroup Relations, 14, 407-428. https://doi.org/10.1177/1368430210387805

West, K., Turner, R., \& Levita, L. (2015). Applying imagined contact to improve physiological responses in anticipation of intergroup interactions and the perceived quality of these interactions. Journal of Applied Social Psychology, 45, 425-436. https://doi.org/10.1111/jasp.12309 
Wilson, T. D., \& Gilbert, D. T. (2005). Affective forecasting: Knowing what to want. Current Directions in Psychological Science, 14, 131-134.

https://doi.org/10.1111/j.0963-7214.2005.00355.x 
Table 1

Means and Standard Deviations of Dependent Measures across Experimental

Conditions in Experiment 1

\begin{tabular}{lccccc}
\hline $\begin{array}{l}\text { Dependent } \\
\text { measures }\end{array}$ & $\begin{array}{c}\text { Imagined } \\
\text { contact }(n= \\
32)\end{array}$ & $\begin{array}{c}\text { Imagined } \\
\text { contact with } \\
\text { factual } \\
\text { message }(n= \\
32)\end{array}$ & $\begin{array}{c}\text { Enhanced } \\
\text { imagined } \\
\text { contact }(n= \\
35)\end{array}$ & $\begin{array}{c}\text { Control }(n= \\
35)\end{array}$ & $\begin{array}{c}\text { Factual } \\
\text { message } \\
\text { only }(n=33)\end{array}$ \\
\hline $\begin{array}{l}\text { Intergroup } \\
\text { anxiety }\end{array}$ & $4.57(0.73)$ & $4.43(0.87)$ & $3.99(0.53)$ & $4.60(0.79)$ & $4.44(0.89)$ \\
$\begin{array}{l}\text { Attitudes } \\
\begin{array}{l}\text { Social } \\
\text { closeness }\end{array}\end{array}$ & $4.35(0.90)$ & $4.36(0.87)$ & $4.29(0.80)$ & $4.21(0.73)$ & $4.43(1.03)$ \\
$\begin{array}{l}\text { Intentions } \\
\text { for future } \\
\text { contact }\end{array}$ & $6.94(1.48)$ & $6.74(1.42)$ & $6.63(1.35)$ & $6.41(1.23)$ & $6.13(1.80)$ \\
\hline
\end{tabular}

Intergroup anxiety and attitudes are on a 7-point scale. Social closeness is on a 4-point scale. Intentions for future contact is on a 9-point scale. 
Table 2

Means, Standard Deviations, and Correlations Between the Measures in

\section{Experiment 1}

\begin{tabular}{lcccc}
\hline Variable & Mean (SD) & 1 & 2 & 3 \\
\hline $\begin{array}{l}\text { 1. Intergroup } \\
\text { anxiety }\end{array}$ & $4.40(0.79)$ & - & - & - \\
& & & & \\
2. Attitude & $4.32(0.86)$ & $-.220^{* *}$ & - & - \\
$\begin{array}{l}\text { 3. Social } \\
\text { closeness }\end{array}$ & $3.14(0.52)$ & $-.300^{* * *}$ & $.369^{* * *}$ & - \\
$\begin{array}{l}\text { 4. Intentions for } \\
\text { future contact }\end{array}$ & $6.57(1.47)$ & $-.240^{* *}$ & $.327^{* * *}$ & $.455^{* * *}$ \\
\hline
\end{tabular}

$n=167 .{ }^{* *} p<.01 .{ }^{* * *} p<.001$. Intergroup anxiety and attitudes are on a 7-point scale.

Social closeness is on a 4-point scale. Intentions for future contact is on a 9-point scale. 
Table 3

Means and Standard Deviations of Dependent Measures across Experimental

Conditions in Experiment 2

\begin{tabular}{lccc}
\hline $\begin{array}{l}\text { Dependent } \\
\text { measures }\end{array}$ & $\begin{array}{c}\text { Enhanced } \\
\text { imagined contact } \\
(n=42)\end{array}$ & $\begin{array}{c}\text { Enhanced } \\
\text { imagined contact } \\
\text { with factual } \\
\text { message } \\
(n=39)\end{array}$ & $\begin{array}{c}\text { Control } \\
(n=40)\end{array}$ \\
\hline $\begin{array}{l}\text { Intergroup } \\
\text { anxiety }\end{array}$ & $4.26(0.85)$ & $4.31(0.91)$ & $4.63(0.84)$ \\
$\begin{array}{l}\text { Attitudes } \\
\begin{array}{l}\text { Social } \\
\text { closeness }\end{array}\end{array}$ & $4.37(0.84)$ & $4.22(1.06)$ & $4.14(0.72)$ \\
$\begin{array}{l}\text { Intentions } \\
\text { for future } \\
\text { contact }\end{array}$ & $6.20(1.23)$ & $3.08(0.67)$ & $3.11(0.56)$ \\
\hline
\end{tabular}

Intergroup anxiety and attitudes are on a 7-point scale. Social closeness is on a 4-point scale. Intentions for future contact is on a 9-point scale. 
Table 4

Means, Standard Deviations, and Correlations Between the Measures in

Experiment 2

\begin{tabular}{lcccc}
\hline Variable & Mean (SD) & 1 & 2 & 3 \\
\hline $\begin{array}{l}\text { 1. Intergroup } \\
\text { anxiety }\end{array}$ & $4.40(0.87)$ & - & - & - \\
2. Attitude & $4.25(0.88)$ & $-.348^{* * *}$ & - & - \\
$\begin{array}{l}\text { 3. Social } \\
\text { closeness }\end{array}$ & $3.09(0.58)$ & $-.442^{* * *}$ & $.518^{* * *}$ & - \\
$\begin{array}{l}\text { 4. Intentions for } \\
\text { future }\end{array}$ & $6.40(1.42)$ & $-.266^{* *}$ & $.409^{* * *}$ & $.521^{* * *}$ \\
$\quad$ contact & & & & \\
\hline
\end{tabular}

$n=121 .{ }^{* *} p<.01 .{ }^{* * *} p<.001$. Intergroup anxiety and attitudes are on a 7-point scale.

Social closeness is on a 4-point scale. Intentions for future contact is on a 9-point scale. 

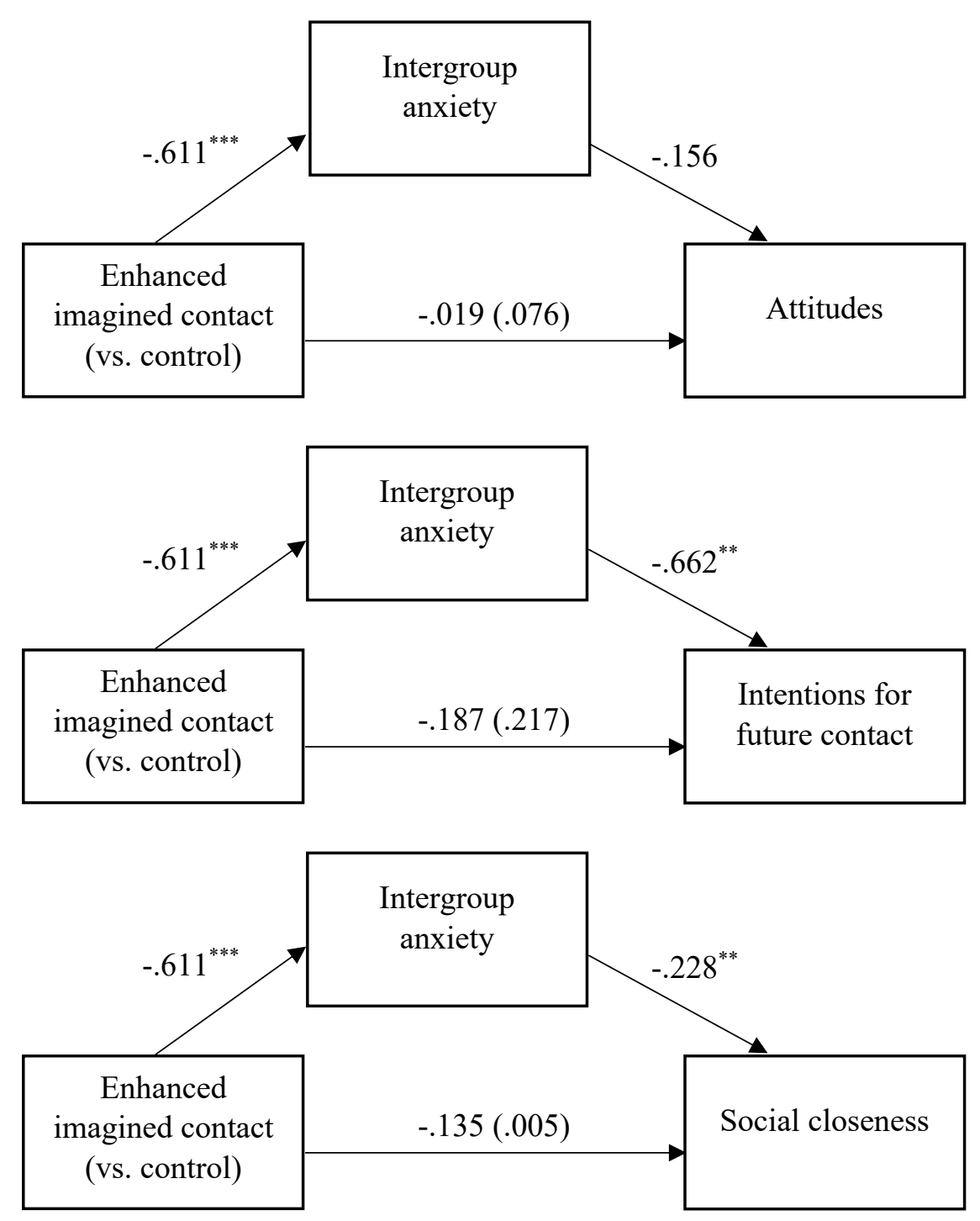

Figure 1. Mediational models of the role of intergroup anxiety in explaining the effects of enhanced imagined contact in Experiment 1. Unstandardised regression coefficients are shown in the models and coefficients of the direct effect without the mediator are shown within the parenthesis. The three panels from top to bottom represent the role of intergroup anxiety on the relationship between enhanced imagined contact and attitudes, intentions for future contact, and social closeness, respectively. ${ }^{* *} p<.01 .{ }^{* * *} p<.001$. 


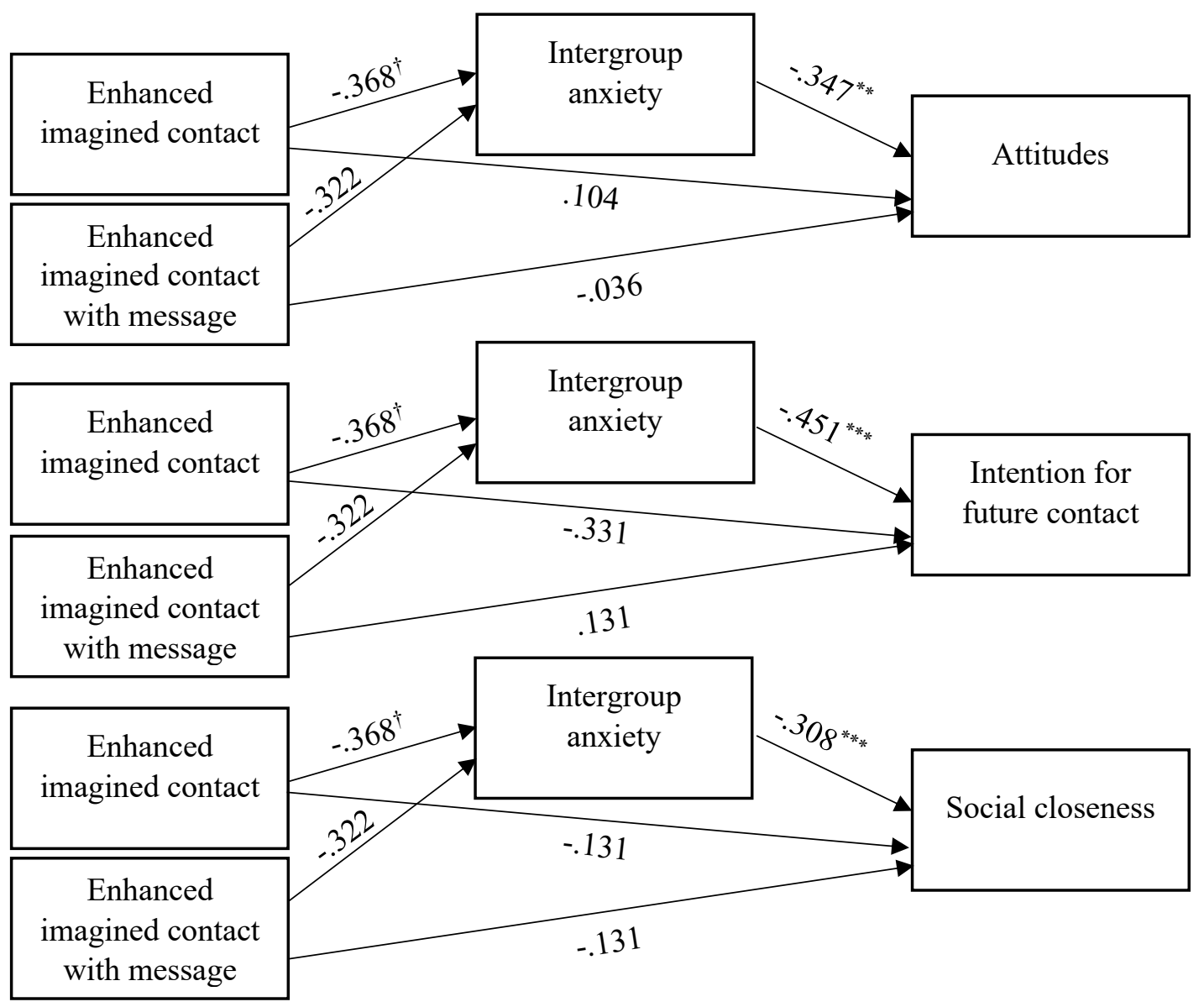

Figure 2. Mediational models presented in path diagram form depicting the role of intergroup anxiety on the effects of enhanced imagined contact in Experiment 2. Unstandardized regression coefficients are shown in the models. The three panels from top to bottom represent the role of intergroup anxiety on the relationship between enhanced imagined contact and attitudes, intentions for future contact, and social closeness, respectively. ${ }^{\dagger} p=.056,{ }^{* *} p<.01,{ }^{* * *} p<.001$. 


\section{Appendix A: Factual message about schizophrenia}

\section{WHAT ISSCHIZOPHRENIA? \\ Chronic and severe mental disorder that affects how a person thinks, feels, and acts}

Affects
Usually begins in adolescence
or young adulthood




\section{Appendix B: Filler}

\section{WHAT IS HEALTHYEATING?}

A healthy lifestyle involves choosing a balanced diet or healthy eating plan.

Unhealthy diet and lack of physical activity are LEADING

GLOBALRISKS to health

Obesity rates have more than DOUBLED over

S! the years

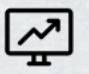

PRINCIPLES - Eat a variety of food, avoid picky eating

OFHEALTHY - Have regular meals

EATING

- Have a balanced diet

- Eat food low in saturated fats, trans fats, cholesterol, salt \& added sugars

- Stay within one's daily calorie needs

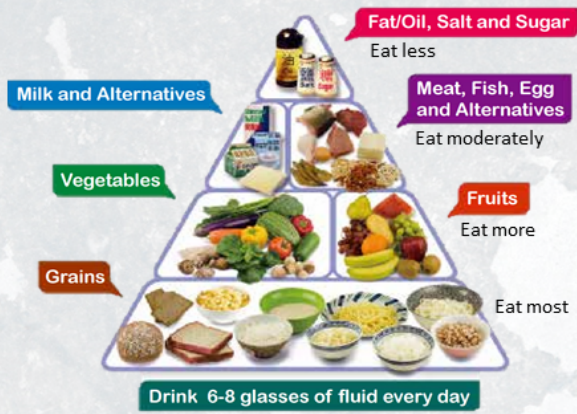

EFFECTS OF Having a healthy diet helps one to:

HEALTHY - Reach and maintain a healthy weight

EATING - Reduce the risk of chronic diseases (e.g. heart disease and cancer)

(y.) - Protect from infections

- Improvesmood and boosts energy

- Promotes overall health 